\title{
RECICLAGEM DE PILHAS PARA REUTILIZAÇÃO DE SEUS COMPOSTOS NO SETOR INDUSTRIAL
}

\author{
Daniel Ângelo Macena, Vinícius Marques Gomes, Bruna de Souza Jéssica Fernanda Rodrigues. \\ Universidade do Oeste Paulista - UNOESTE, Curso de Química Bacharelado, Presidente Prudente, SP. E-mail: \\ danielangelo@live.com.
}

\section{RESUMO}

As pilhas levam cerca de 500 anos para ser absorvida no ambiente, isto causa grandes danos ambientais relacionados à saúde humana. Este trabalho teve como objetivo aplicar um método de reciclagem de pilhas usadas e propor a reutilização dos resíduos metálicos no setor industrial. Para a recuperação dos metais foi realizada a separação de todos os componentes da pilha, e em seguida, a recuperação quantitativa de metais, como o zinco à sua forma metálica, e o manganês como matriz de cimento. Para os resultados da recuperação de zinco foi uma média de $55 \%$ e a matriz de cimento sob teste de compressão, o valor da capacidade máxima suportada foi uma média de $20,3 \mathrm{Kg}$. Conclui-se que houve respostas positivas do estudo proposto para a recuperação de zinco e inserção de resíduos em matriz de cimento, o que pode ser uma alternativa para disposição final de resíduos de pilha.

Palavras-chave: Descarte inadequado; Ambiente; Saúde; Recuperação de metais, Pilhas.

\section{RECYCLING OF BATTERIES FOR REUSE OF ITS COMPOUNDS IN THE INDUSTRIAL SECTOR}

\begin{abstract}
The piles take about 500 years to be absorbed into the environment, this is what causes great environmental damage related to human health. This work had as objective apply a method of recycling used piles and propose the reuse of metallic waste in the industrial sector. For the recovery of metals all components of the piles were separated and then the quantitative recovery of metals, such as zinc to its metallic form, and manganese as cement matrix. For the results of the zinc recovery was an average of $55 \%$ and the cement matrix under compression test, the value of the maximum supported capacity was an average of $20.3 \mathrm{Kg}$. It was concluded that there were positive responses from the proposed study for recovery of zinc and the insertion of residues in cement matrix, which can be an alternative for final disposal of pile residues.
\end{abstract}

Keywords: Inappropriate disposal, Environment; Health; Recovery of metals; Piles. 


\section{INTRODUÇÃO}

Com o desenvolvimento tecnológico, a procura por pilhas no mercado aumenta, acarretando, ao final, em um grande número de pilhas descartadas inadequadamente, conhecidamente como resíduo pós-consumo, causando a contaminação do ambiente, além de riscos à saúde humana, devido à má gestão de resíduos sólidos e (GIARETTA et al., 2010).

Todavia, esse desenvolvimento tecnológico é o que provoca grande preocupação ambiental, tanto pelo descarte inadequado como por gerar grande quantidade de resíduo eletroeletrônico, incluindo bateria e as pilhas. A NBR 10.004 classifica as baterias e pilhas como resíduo de classe I, ou seja, resíduos perigosos que portam características corrosivas, reativas e tóxicas. Referente à saúde e meio ambiente, muitos países foram motivados a classificar as pilhas como resíduos perigosos firmando rígidas legislações na tentativa de reduzir metais potencialmente tóxicos como Mercúrio, Cádmio e Chumbo (DA SILVA et al., 2011).

A Resolução do Conama no 401/2008 é a legislação que regulamenta sobre Resíduo de pilhas e baterias no Brasil, estabelecendo valor máximo permitido de Chumbo, Cádmio e Mercúrio, que são comercializados em todo o território nacional, gerenciamento e disposição final desses resíduos.

Atualmente, os limites aceitáveis pela Resolução 401/2008, que revoga a resolução 257/1999, e diz que pilhas do tipo zinco-carbono e alcalinas de manganês devem conter traços de até $0,1 \%$ em peso de chumbo, $0,002 \%$ em peso de cádmio e $0,0005 \%$ em peso de mercúrio em sua composição.

De acordo com o Art.18 da Resolução no 401/2008 deve tanto os fabricantes como importadores dos produtos abrangidos por esta Resolução proporcionar a formação e capacitação dos recursos humanos inseridos neste grupo de atividade, até mesmo catadores de resíduos, sobre os métodos e técnicas de logística reversa com a disposição ambientalmente adequada de seus produtos.

A Logística Reversa tornou-se de extrema pertinência dentro das empresas. De acordo com Shi et al. (2012), deve-se seguir algumas etapas para a implantação de um sistema de Logística Reversa de pilhas e baterias: coletar, armazenar, transportar, classificar, descaracterizar e processar, reaproveitar metais e não metais.

Segundo Lizarelli e De Milano (2014), a logística reversa ainda merece um pouco mais de reconhecimento e adesão pelas empresas que produzem e importam esses produtos, tais como, pilhas. Na finalidade de amplificar o círculo de consumidores sensibilizados.

As pilhas levam cerca de 500 anos para que sejam absorvidas no ambiente, é isto que causa grandes danos ambientais relacionados à saúde humana, sendo eles, problemas cardíacos e pulmonares, distúrbios digestivos, osteoporose, disfunção renal e depressão. É pouco conhecimento das pessoas sobre as causas e riscos devido à contaminação das substâncias que compõem as pilhas (GOUVEA; FIALHO; MIGUEL, 2010).

Desta forma, este trabalho teve como objetivo aplicar um método de reciclagem de pilhas usadas e propor a reutilização dos resíduos metálicos no setor industrial.

\section{METODOLOGIA}

\section{Coleta de Pilhas e Obtenção dos Metais}

A parte experimental do projeto foi realizada com pilhas do tipo comum (zinco-carbono), e teve como referência a metodologia utilizada por Wolff e Conceição (2011). Estabeleceu o uso de pilha do tipo comum devido a preferência e/ou maior uso por grande parte da população e, por consequência, maior quantidade de descarte.

Para a obtenção do material, foi realizada uma campanha em escolas do município de Presidente Prudente para o recolhimento das pilhas utilizadas. Depois de realizada a coleta das 
pilhas, as mesmas foram abertas de forma manual, e seus componentes foram separados e identificados.

\section{Recuperação do Zinco}

O zinco misturado ao dióxido de manganês na forma de óxido e cloreto de zinco foi primeiramente lixiviado, pra que então pudesse ser empregada a eletrólise.

\section{Solubilização}

Inicialmente foi realizada a homogeneização de $46,04 \mathrm{~g}$ da polpa da pilha, com o auxilio de um almofariz e pistilo. Em seguida, o material homogeneizado foi colocado em um béquer de 250 $\mathrm{mL}$, acrescentando água deionizada. A mistura foi então deixada em repouso por duas horas, sendo realizadas misturas periódicas para que o sólido entrasse em total contato com a água. Após o tempo de repouso, colocou-se a mistura em uma manta aquecedora, em uma temperatura de 90 - por 30 minutos. Passado o tempo de aquecimento, deixou-se a mistura mais uma vez em repouso, até que se atingisse temperatura ambiente e então, realizou a filtração da solução.

\section{Lixiviação em Meio Ácido}

Realizou-se a homogeneização de aproximadamente $365 \mathrm{~g}$ da polpa da pilha. Esta polpa foi transferida para um béquer de $2000 \mathrm{~mL}$, sendo acrescentado cerca de $500 \mathrm{~mL}$ de ácido sulfúrico $50 \%$. Deixou-se a mistura em repouso por 2 horas, sendo agitada periodicamente. Aqueceu-se a mistura a 90 ㅇ durante 30 minutos em chapa aquecedora. Após o aquecimento, esperou-se até o resfriamento da mistura a temperatura ambiente, e então, filtrada e armazenada.

\section{Eletrólise}

Para a eletrólise, foi utilizado eletrodos de carbono e zinco da própria pilha. O eletrodo de carbono é o cátodo, e o de zinco o ânodo.

No estabilizador de corrente, empregou-se uma voltagem de 0,2 A, durante 90 (noventa) minutos, empregando-se uma distância de $2 \mathrm{~cm}$ entre as placas. Em um béquer de $250 \mathrm{~mL}$, colocou-se o filtrado resultante da solubilização (Figura 1).

Figura 1. Banho eletrolítico da placa de zinco
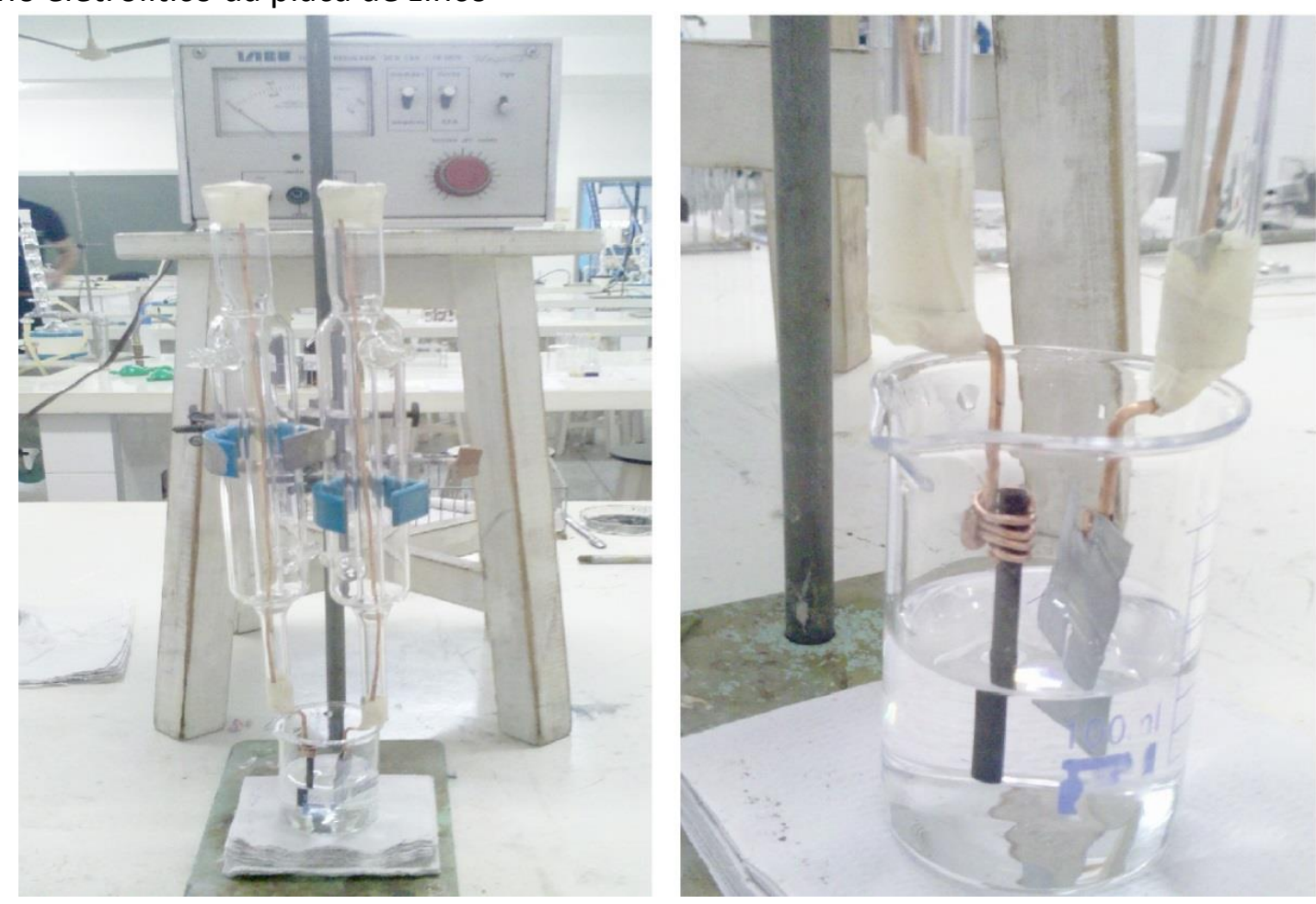

Fonte: Próprio autor. 
Fusão

Pesou-se $6 \mathrm{~g}$ da sucata de zinco e transferida para um cadinho de porcelana, e procedeu-se a adição de $6 \mathrm{~g} \mathrm{NH}_{4} \mathrm{Cl}$ (Cloreto de Amônio), para a remoção de impurezas presentes na sucata. O cadinho com sucata e sal foi levado à mufla, em uma temperatura de 500 oC por aproximadamente 4 horas. Após o tempo de mufla mantido em dessecador até o completo resfriamento.

\section{Recuperação do Dióxido de Manganês de Pilhas Comuns}

O resíduo resultante da solubilização e lixiviação foi inertizado pelo processo de solidificação, realizando a solidificação em matriz de cimento.

\section{Matriz de Cimento}

O resíduo proveniente da lixiviação e da solidificação foi seco em estufa numa temperatura de 90 드, durante 24 horas, macerado com almofariz e pistilo e peneirado $(0,59 \mathrm{~mm})$. Do resíduo final foram utilizados $100 \mathrm{~g}$ do material e o mesmo processo foi realizado utilizando argila e utilizado $25 \mathrm{~g}$.

A massa foi preparada a partir de $225 \mathrm{~g}$ de cimento, os materiais pesados anteriormente e água deionizada, até que a mistura ficasse homogênea (quantidade para a preparação de três matrizes de cimento) e colocadas em moldes de PVC, com altura de $10 \mathrm{~cm}$ e diâmetro de $3,4 \mathrm{~cm}$, lubrificados com vaselina, evitando assim que a massa se prendesse nos moldes quando seca. Deixou-se a massa secando naturalmente por aproximadamente 24 horas. Por fim, foram retiradas dos moldes e submetidas ao teste de compressão.

\section{RESULTADOS}

Na eletrólise houve a formação de gás hidrogênio e deposição de metal ao redor da placa de zinco. Ocorreu a liberação de cloro gasoso e deposição de oxigênio no bastão de grafite.

$\mathrm{Na}$ Tabela1 pode-se observar que houve respostas para e recuperação de zinco em uma média geral de $55,6 \%$.

Tabela 1. Porcentagem de zinco recuperado pela fusão.

\begin{tabular}{|c|c|c|c|}
\hline AMOSTRAS & MZI* (g) & MZF** $^{*}(\mathbf{g})$ & RECUPERAÇÃO (\%) \\
\hline $\mathbf{A}_{\mathbf{1}}$ & 6,0224 & 3,2863 & 55 \\
\hline $\mathbf{A}_{\mathbf{2}}$ & 6,2352 & 3,5549 & 57 \\
\hline \hline $\mathbf{A}_{\mathbf{3}}$ & 6,1527 & 3,3582 & 55 \\
\hline
\end{tabular}

Fonte: Dados experimentais

Nota:*Média de zinco inicial, **Média de zinco final.

As matrizes de cimento apresentaram valores diferentes de carga suportada, apesar de ser a mesma massa, conforme a Tabela 2 é possível observar que a carga máxima suportada foi de $20,3 \mathrm{Kg}$.

Tabela 2. Carga suportada pelos blocos de concreto contendo resíduo.

\begin{tabular}{|c|c|}
\hline MC & CMS (kg) \\
\hline 1 & 20 \\
\hline 2 & 18 \\
\hline \hline 3 & 23 \\
\hline
\end{tabular}

Fonte: Dados experimentais

Nota: $\mathrm{MC}=$ Matriz de Cimento; $\mathrm{CMS}=$ Carga máxima suportada. 


\section{DISCUSSÃO}

A formação do gás Hidrogênio e a deposição de metal em torno da placa de zinco foi resultado da redução de moléculas de água, como observado na reação abaixo:

$$
2 \mathrm{H}_{2} \mathrm{O}+\mathrm{e}^{-} \rightarrow \mathrm{H}_{2}+2 \mathrm{OH}^{-}
$$

O metal depositado no cátodo (eletrodo de Carbono) é resultado da redução do zinco presente no eletrólito:

$$
\mathrm{Zn}^{2+}+2 \mathrm{e}^{-} \rightarrow \mathrm{Zn}
$$

A média de zinco final está proporcional em relação à média de zinco inicial das amostras, levando em consideração a ordem de massas iniciais e finais, prevalece ainda $A_{2}>A_{3}>A_{1}$. Houve uma resposta de recuperação podendo então, parte do zinco voltando a sua forma natural que é o zinco metálico, deixando de ser apenas um resíduo de pilha.

Um estudo por Cantarino (2011) propôs a recuperação de zinco em Lamas de Aciaria LD ao qual se utilizou do processo de fusão e lixiviação e obteve uma recuperação de $80 \%$ de zinco por precipitação.

O corpo de prova (matriz de cimento) sempre deve ser padronizado a uma forma cilíndrica, completamente preenchida e sobre uma superfície nivelada, além de armazenamento adequado conforme NBR 5738 (Norma Brasileira). Para 28 dias, a matriz de cimento atinge a sua resistência característica, enquanto que no ensaio após 24 horas de secagem foi suficiente para suportar uma média de carga máxima de $20,3 \mathrm{Kg}$.

\section{CONCLUSÃO}

Conclui-se que houve respostas positivas do estudo proposto para a recuperação de zinco e inserção de resíduos em matriz de cimento, o que pode ser uma alternativa para disposição final de resíduos de pilha. Sugerem-se também estudos mais aprofundados para uma melhor eficiência na recuperação do zinco e resistividade da matriz de cimento. O plástico, papelão, latão, carbono podem ser reprocessados, retornado ao processo de produção de pilhas, ou utilizados para outros fins.

\section{REFERÊNCIAS}

CANTARINO, M. V. Estudo da remoção de zinco e de álcalis contidos em lamas de aciaria LD. Master of Science Thesis, UFMG, Belo Horizonte, Brazil, p. 97, 2011.

DA SILVA, B. O., CÂMARA, S. C., AFONSO, J. C., NEUMANN, R., \& NETO, A. A. Série histórica da composição química de pilhas alcalinas e zinco-carbono fabricadas entre 1991 e 2009. Quim. Nova, v. 34, n. 5, p. 812-818, 2011.

GIARETTA, J. B. Z., TANIGUSHI, D. G., SERGENT, M. T., VASCONCELLOS, M. D. P., \& GÜNTHER, W. M. R.. Habits related to the post-consumption discard of mobile phones and their batteries within an academic community. Saúde e Sociedade, v. 19, n. 3, p. 674-684, 2010.

GOUVEA, P. A.; FIALHO, S. S. D. A. L.; MIGUEL, J. R. Impactos ambientais causados pelo descarte inadequado de pilhas e baterias. Saúde \& Ambiente em Revista, v. 4, n. 2, p. 39, 2010.

LIZARELLI, F. L.; DE MILANO, C. B. Mapeamento da Logística Reversa de pilhas e baterias: estudo de caso de um projeto proposto por uma instituição bancária. Gepros: Gestão da Produção, Operações e Sistemas, v. 9, n. 1, p. 115, 2014.

NBR, ABNT. 5738-Concreto-Procedimento para moldagem e cura de corpos-de-prova. Rio de Janeiro, 2003. 
RESOLUÇÃO, №. 408, de 04 de Novembro de 2008. CONAMA-Conselho Nacional de Meio Ambiente, 2004.

SHI, X., LI, L. X., YANG, L., LI, Z., \& CHOI, J. Y. Information flow in reverse logistics: an industrial information integration study. Information Technology and Management, v. 13, n. 4, p. 217-232, 2012.

WOLFF, E.; CONCEIÇÃO, S. V. Resíduos sólidos: a reciclagem de pilhas e baterias no Brasil. Anais. XXXI Encontro Nacional de Engenharia de Produção-ENEGEP. Belo Horizonte, 2011. 